Article

\title{
Mathematical Modeling and Simulation of a Gas Emission Source Using the Network Simulation Method
}

\author{
Juan Francisco Sánchez-Pérez ${ }^{1, * \mathbb{D}}$, María Rosa Mena-Requena ${ }^{1}$ and Manuel Cánovas ${ }^{2}$ (D) \\ 1 Department of Applied Physics and Naval Technology, Universidad Politécnica de Cartagena (UPCT), \\ 30202 Cartagena, Spain; mr.mena.requena@gmail.com \\ 2 Metallurgical and Mining Engineering Department, Universidad Católica del Norte, \\ Antofagasta 1240000, Chile; manuel.canovas@ucn.cl \\ * Correspondence: juanf.sanchez@upct.es
}

Received: 15 October 2020; Accepted: 6 November 2020; Published: 9 November 2020

\begin{abstract}
A mathematical model for the simulation of the diffusion of the pollutants released from a point source is presented. All phenomena have been included, such as thermal and wind gradients, turbulence, fumigation, convective and diffusive effects, and atmospheric stabilities. To better understand the dynamics of these occurrences, the Network Simulation Method was used to provide the concentration of pollutants in three spatial coordinates. The model was simulated in open source software and validated with experimental data, satisfying the Hanna criteria. Additionally, this model selects for the appropriate expressions based on the physical phenomena that govern each case and allows for time-dependent data entry. The cases studied show the great coupling that exists between the variables of wind velocity and atmospheric stability for the pollutant diffusion. The model can be used for two important aims, to identify the behavior of the emission of pollutants, and to determine the concentration of a pollutant at various points, through an inverse problem, locating the source of the emission.
\end{abstract}

Keywords: network simulation method; numerical methods; emission of pollutants; outdoor air pollution; diffusion

\section{Introduction}

Air pollution is understood as the existence of potentially harmful matter suspended in the air, which can be classified into basic chemical compounds (oxides of sulfur or nitrogen, carbon monoxide), particulate matter, high-risk radioactive compounds, or suspensions from a biological source, such as bacteria. All of which can produce harmful effects on the health of a population.

In all cases, the atmospheric dispersion of pollutants is essentially dependent on the air flow or wind velocity in the lower layers of the atmosphere. This dispersion represents an important environmental engineering problem in relation to the health of a population, particularly in areas where different pollution sources can be unhealthy and/or dangerous [1,2]. In city centers where the building density is high, emissions from chimneys accumulate in the open spaces between buildings due to the higher velocity of air flow and its turbulent nature in comparison with the open spaces.

For years, the main objective was to monitor the concentration of pollutants at each point in space and at each moment as a result of the dispersion caused by the movement of the atmospheric air in which the pollutants are suspended. The modeling of the atmospheric dispersion of pollutants elicits the mathematical and/or numerical study of these processes, seeking analytical or semi-analytical solutions that present increasingly accurate results. 
After analyzing the behavior of smoke in numerous experiments for various types of emissions, Roberts [3], in 1923, proposed solutions for a steady state based on normal or Gaussian distributions of concentration, always under conditions of constant wind velocity and assuming that the coefficients of which the dispersion depended upon were constant. Thereby, it was possible to characterize the dispersions by means of standard deviations, giving rise to statistical models. All the expressions proposed by this author serve as the basis for more precise developments of passive dispersion models.

In 1953, Sutton [4] introduced the so-called Sutton diffusion coefficients, which can be considered as meteorological constants and decrease significantly with height, and the Sutton diffusion index which depends on the conditions of stability. Between 1961 and 1982, Pasquill [5-7] introduced a set of recommendations and guides for the determination of the different coefficients that depend on the class of atmospheric stability. Finally, Gifford [8], in 1961, modified the Pasquill model, giving rise to the Pasquill-Gifford model, introducing meteorological constants or dispersion coefficients, which represent the standard deviations in the wind directions $[8,9]$. Later, these coefficients were refined and discussed by Slade [10] and Turner [11].

However, the approximations provided are not devoid of error in their results. Thereby, the so-called gradient transfer models were introduced, such as the one presented in this work, which includes relationships that provide the changes of the diffusivities, of the temperatures, and of the wind velocity with the height and atmospheric stability, implementing increasingly complex equations that depend on a greater number of variables. These models lack an analytical solution and, hence, are solved by numerical simulations and validated with experimental data [12].

Therefore, the release of pollutants from a point sources poses a risk to the population, as there is an increase in concentration in a certain area, reaching in some cases, values higher than those recommended by international organizations. The use of the most accurate possible models that allow predicting the behavior of the pollutant once released allows for control and minimizes the risks for the population. In 2016, outdoor air pollution in both rural areas and cities around the world was reported to cause millions of premature deaths each year. The World Health Organization (WHO) estimates that approximately $58 \%$ of them were due to heart disease, $18 \%$ to pulmonary disease, and $6 \%$ to lung cancer [13].

The aims of this article are twofold: based on current bibliographies, we developed the most complete mathematical model to obtain the concentration of a pollutant that has been released at any point in space. Secondly, we developed an efficient and precise network method to solve the aforementioned mathematical model to be simulated in free software for circuit analysis, such as NgSpice [14], without linearization of the equations or making assumptions. Thus, the Network Simulation Method, the tool exploited in this work, has been used in numerous areas of engineering and science, demonstrating its effectiveness and reliability in addressing problems, such as dry friction, electrochemistry, oxidation processes, inverse problems, fluid flow transport, etc. [15-21].

\section{Mathematical Model}

The movement of pollutants released from a source involves numerous phenomena, such as turbulence, wind dragging, buoyancy forces, diffusive effects, etc. The governing equation that encompasses them is given by the following expression [12,22-24]:

$$
\frac{\partial c_{p}}{\partial t}+\frac{\partial\left(u_{x} c_{p}\right)}{\partial x}+\frac{\partial\left(u_{y} c_{p}\right)}{\partial y}+\frac{\partial\left(u_{z} c_{p}\right)}{\partial z}=\frac{\partial}{\partial x}\left(K_{x} \frac{\partial c_{p}}{\partial x}\right)+\frac{\partial}{\partial y}\left(K_{y} \frac{\partial c_{p}}{\partial y}\right)+\frac{\partial}{\partial z}\left(K_{z} \frac{\partial c_{p}}{\partial z}\right)+R_{c}+Q_{p}
$$

where $c_{p}$ is the pollutant concentration in $\left(\mu g / m^{3}\right), u_{x}, u_{y}$, and $u_{z}$ are the wind velocities in the different space directions, $\mathrm{x}, \mathrm{y}$, and $\mathrm{z}$, respectively, $\mathrm{K}_{\mathrm{x}}, \mathrm{K}_{\mathrm{y}}$, and $\mathrm{K}_{\mathrm{z}}$ are the diffusivity parameters in the different directions of space, $R_{c}\left(\mu \mathrm{g} / \mathrm{m}^{3} \mathrm{~s}\right)$ is the term of reaction or decay due to physicochemical reactions in the atmosphere that depend on each pollutant [25], and $Q_{p}\left(\mu \mathrm{g} / \mathrm{m}^{3} \mathrm{~s}\right)$ is the term that implements the source or sink of the pollutant. This last variable represents the emission of the polluting gas, and can 
be a continuous emission and take a constant value over time; it can be a quick release, that is, of a short period of time; it can be an instantaneous emission; or it can be variable as a function of time.

Illustratively, Figure 1 is a schematic representation of the model showing the diffusion of the pollutant emitted by a point source in the direction of the wind, whose behavior is defined by Equation (1). Being an unbound medium, it is represented by a space large enough so that the pollutant diffusion does not reach the boundary. The different processes involved, as well as the boundary conditions, will be described in the next sections.

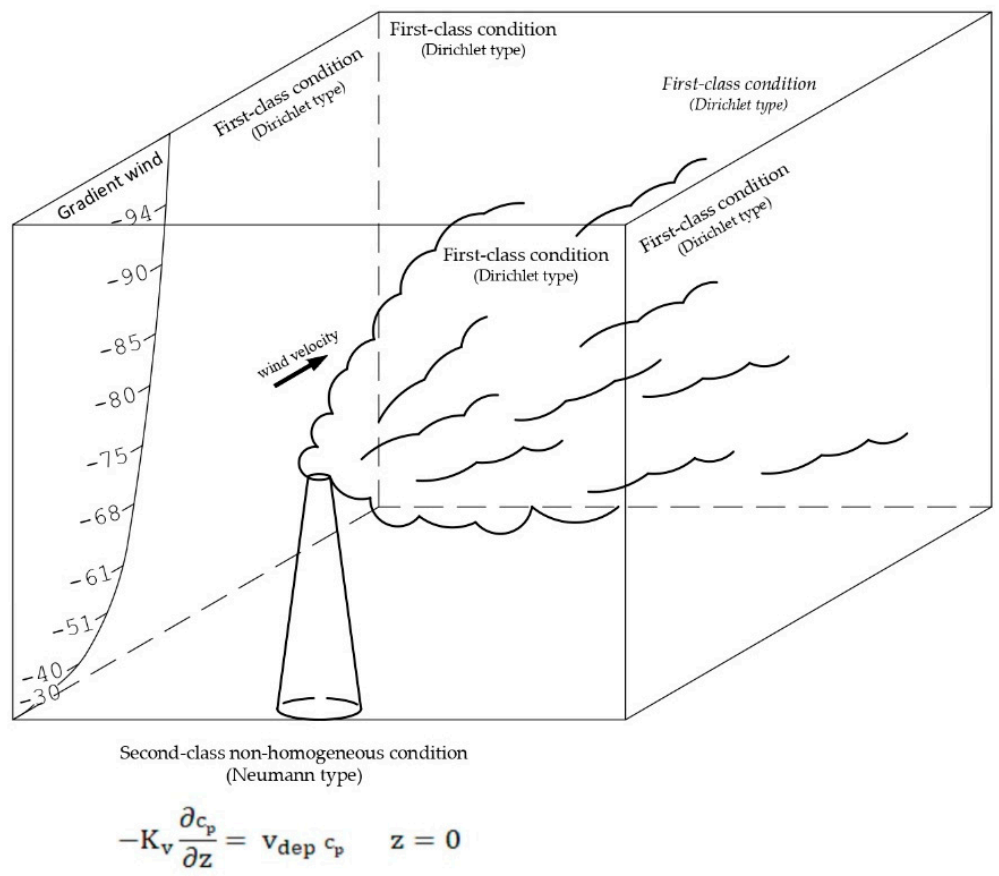

Figure 1. Schematic representation of the model.

\subsection{Atmospheric Stability}

Stability conditions (which can be classified as neutral, stable or subadibatic, and unstable or superadibatic) define the atmospheric parameters. In neutral conditions, the buoyancy forces can be considered negligible while the drag forces of the wind on the earth's surface, together with the effects derived from the change of direction and wind velocity with height, are the cause of turbulent energy transport. In unstable conditions, the buoyancy forces induced by heat flows are added to the above. Stable conditions occur at night, where the surface cools more than the air itself. Given the limitation of the division of stability into three groups, Pasquill [22] established a subdivision into atmospheric stability categories, whose relationship with stability is shown in the following table (Table 1):

Table 1. Relationship between stability and the category of atmospheric stability [22].

\begin{tabular}{cc}
\hline Stability & Pasquill's Stability Categories \\
\hline Unstable (UB) & A, B, and C \\
Neutral (NL) & D \\
Stable (SB) & E, F, and G \\
\hline
\end{tabular}

The category of atmospheric stability is a function of different parameters, among which insolation, wind velocity, and cloudiness stand out (Table 2) [22]. Wind velocity is usually measured at a reference height, $\mathrm{v}_{\text {ref }}$, typically $10 \mathrm{~m}\left(\mathrm{z}_{\mathrm{ref}}\right)$, cloudiness is expressed as a percentage, and finally, insolation is a function of solar radiation and is established according to the following table (Table 3). 
Table 2. Pasquill's stability categories depending on different parameters [22].

\begin{tabular}{cccccc}
\hline \multirow{2}{*}{$\mathbf{u}_{\mathbf{r e f}=\mathbf{m}(\mathbf{m} / \mathbf{s})}$} & \multicolumn{3}{c}{ Day } & \multicolumn{2}{c}{ Night } \\
\cline { 2 - 6 } & Strong & Moderate & Slight & $\mathbf{2 5 0 \%}$ & $<\mathbf{5 0 \%}$ \\
\cline { 2 - 6 } & A & A-B & B & F & G \\
\hline 2 & A-B & B & C & E & F \\
$2-3$ & B & B-C & C & D & E \\
$3-5$ & C & C-D & D & D & D \\
$5-6$ & C & D & D & D & D \\
$>6$ & & & &
\end{tabular}

Table 3. Relationship between solar radiation and insolation [26].

\begin{tabular}{cc}
\hline Solar Radiation $\left(\mathbf{W} / \mathbf{m}^{\mathbf{2}}\right)$ & Insolation \\
$>500$ & Strong \\
$300-500$ & Moderate \\
$<300$ & Slight \\
\hline
\end{tabular}

It is the solar radiation itself that establishes whether it is day or night. Thus, Table 2 can be expressed in terms of the three groups of stabilities: unstable, neutral, and stable (Table 4).

Table 4. Atmospheric stability depending on different parameters.

\begin{tabular}{cccccc}
\hline & \multicolumn{3}{c}{ Day } & \multicolumn{2}{c}{ Night } \\
\cline { 2 - 6 } $\mathbf{v}_{\mathbf{r e f}=\mathbf{~} \mathbf{1 0} \mathbf{m}(\mathbf{m} / \mathbf{s})}$ & \multicolumn{3}{c}{ Insolation } & \multicolumn{2}{c}{ Cloudiness } \\
\cline { 2 - 6 } & Strong & Moderate & Slight & $\mathbf{2 5 0}$ & $<\mathbf{5 0} \%$ \\
\cline { 2 - 6 } & UB & UB & UB & SB & SB \\
$2-3$ & UB & UB & UB & SB & SB \\
$3-5$ & UB & UB & UB & NL & SB \\
$5-6$ & UB & UB-NL & NL & NL & NL \\
$>6$ & UB & NL & NL & NL & NL \\
\hline
\end{tabular}

\subsection{Vertical Heat Flux}

This flux, $\mathrm{H}\left(\mathrm{W} / \mathrm{m}^{2}\right)$, is obtained from the energy balance in the ground-the energy received from outside minus the energy emitted. The phenomenon is depreciable for neutral conditions, but it is significant for other conditions. The importance of this flux lies in the effect it has on turbulence through buoyancy effects. Some authors, such as Holtslag and van Ulden [27], considered the fraction of heat absorbed by the water that is invested in evaporation without changing the ground temperature, a phenomenon that, in turn, conditions the temperature of the outside air. Other authors, such as Clarke, established it through the following expression [28].

$$
\mathrm{H}=0.4 \cdot\left(\mathrm{R}_{\mathrm{solar}}-100\right)
$$

where $R_{\text {solar }}$ is the incoming solar radiation $\left(\mathrm{W} / \mathrm{m}^{2}\right)$. The importance of parameter $\mathrm{H}$ lies in its influence on turbulence, since if $\mathrm{H}>0$, the received energy is higher than that emitted (heating of the ground) and the atmosphere is superadibatic; if $\mathrm{H} \leq 0$, it is subadibatic (cooling of the ground); and finally, if $\mathrm{H} \approx 0$, it is a neutral atmosphere. 


\subsection{Wind Profiles}

At levels close to the surface, the wind velocity is influenced by the effects of friction to a greater or lesser degree, being greater during the day, since these effects are determined by the topography and surface roughness (distribution and average height of the obstacles). The gradient decrease with height, showing a greater fall during the day. Thus, according to the American Society of Mechanical Engineers (ASME) [29], the velocity profiles have the shape indicated in Figure 2. The slope of these curves represents the inverse of the velocity gradient with height. By increasing the size of the obstacles, the velocities increase more slowly with the height.

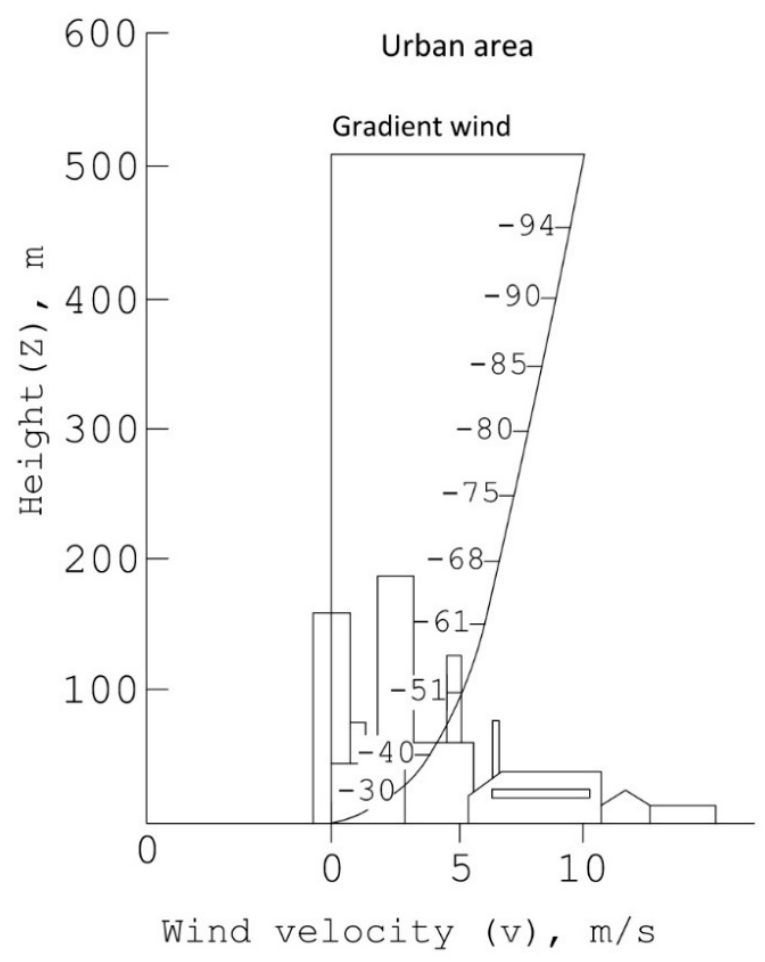

Figure 2. The wind velocity profile [22].

As can be seen in Figure 2, there is turbulence of a mechanical origin associated with the horizontal components of the wind velocity, which is represented by the so-called friction velocity $\mathrm{V}_{*}$. As $\mathrm{V}_{*}$ increases, so does the turbulence and the intensity with which the wind components mix. Thus, in order to use the law of the wall $\frac{\partial \mathrm{v}}{\partial \mathrm{z}}=\frac{\mathrm{v}_{*}}{\mathrm{kz}}$, we need to determine $\frac{\partial \mathrm{v}}{\partial \mathrm{z}}$ or, what is the same, the velocity profile $\left(v_{z}\right)$ as a function of the height $(z)$ [22]. The constant $k$ was determined by von Karman [30-32] and takes a value of 0.35 . The velocity profile gives us the magnitude of the velocity at each height $\left(v_{z}\right)$, which can be decomposed into its $x$ and $y$ components $\left(u_{x}\right.$ and $\left.u_{y}\right)$ through the wind angle with respect to the problem coordinate system, as seen in Figure 3. Regarding the vertical velocity of the wind, $\mathrm{u}_{\mathrm{z}}$, it is assumed to be practically zero [12,22]. 


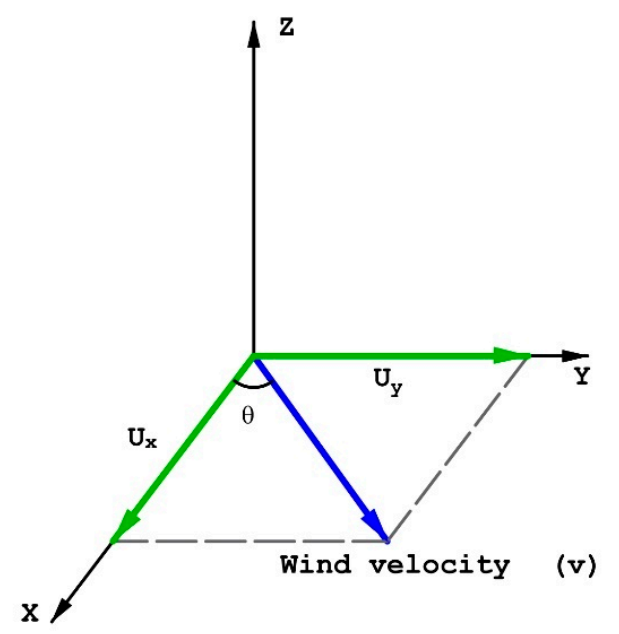

Figure 3. The wind velocity components at a given height $\mathrm{z}$.

To determine the velocity profile, the modified logarithmic or potential approximation can be used. The first one takes into account the predominant floating effects, introducing a Monin-Obukhov length $(\mathrm{L})$ and a dimensionless length $(\mathrm{z} / \mathrm{L})$ known as the Monin-Obukhov parameter [33]. In this way, the law of the wall is modified as follows

$$
\frac{\partial \mathrm{v}}{\partial \mathrm{z}}=\frac{\mathrm{v}_{*}}{\mathrm{kz}} \phi_{\mathrm{M}}=\frac{\mathrm{v}_{*}}{\mathrm{kz}}\left(1+\alpha_{1} \frac{\mathrm{z}}{\mathrm{L}}\right)^{\alpha_{2}}
$$

where $\phi_{M}$ is a turbulent exchange coefficient due to mass. In this way, the wind profiles are based on atmospheric stabilities [31]. Thus, for neutral conditions, $\alpha_{1}$ and $\alpha_{2}$ take null values, 4.7 and 1 , respectively, for stable conditions, and finally, -15 and -0.25 , respectively, for unstable conditions [31]. Other authors, such as Dyer and Hicks [34] and Webb [35], have also adjusted these values.

When solving the integral, the integration constant $\left(\mathrm{z}_{\mathrm{o}}\right)$ appears, which is called the roughness length. On aerodynamically rough surfaces, the velocity profiles are basically dependent on the roughness length, that is, on the distribution and height of rough elements (obstacles). This length takes different values depending on the terrain, such as in open spaces, forests, cities, and so on [22]. Thus, the solution for each of the atmospheric stabilities is given by the following:

$$
\begin{gathered}
\mathrm{v}=\frac{\mathrm{v}_{*}}{\mathrm{k}} \log \left(\frac{\mathrm{z}}{\mathrm{z}_{\mathrm{o}}}\right) \quad \text { neutral stability, } \\
\mathrm{v}=\frac{\mathrm{v}_{*}}{\mathrm{k}}\left(\log \left(\frac{\mathrm{z}}{\mathrm{z}_{\mathrm{o}}}\right)+4.7 \frac{\mathrm{z}-\mathrm{z}_{\mathrm{o}}}{\mathrm{L}}\right) \quad \text { stable stability, } \\
\mathrm{v}=\frac{\mathrm{v}_{*}}{\mathrm{k}}\left(\log \left(\frac{\sqrt[4]{1-\frac{15 z}{\mathrm{~L}}}-1}{\sqrt[4]{1-\frac{15 \mathrm{z}}{\mathrm{L}}}+1}\right)-\log \left(\frac{\sqrt[4]{1-\frac{15 \mathrm{z}_{\mathrm{o}}}{\mathrm{L}}}-1}{\sqrt[4]{1-\frac{15 \mathrm{z}_{\mathrm{o}}}{\mathrm{L}}}+1}\right)+2 \operatorname{tg}^{-1} \sqrt[4]{1-\frac{15 \mathrm{z}}{\mathrm{L}}}-2 \operatorname{tg}^{-1} \sqrt[4]{1-\frac{15 \mathrm{z}_{\mathrm{o}}}{\mathrm{L}}}\right) \quad \text { unstable stability. }
\end{gathered}
$$

The potential approximation for the velocity profile is given by the following expression

$$
\mathrm{v}=\mathrm{v}_{\text {ref }}\left(\frac{\mathrm{z}}{\mathrm{z}_{\text {ref }}}\right)^{\mathrm{p} \text {-index }} \quad \mathrm{z}<\mathrm{z}_{\text {ref }}
$$

where the p-index is a parameter that depends on the Pasquill atmospheric stability category (Table 5) [5]. 
Table 5. The p-index for each category of atmospheric stability [22].

\begin{tabular}{cc}
\hline Pasquill Stability Category & p-Index \\
\hline A & 0.33 \\
B & 0.26 \\
C & 0.20 \\
D, E & 0.38 \\
F & 0.42 \\
G & 0.57 \\
\hline
\end{tabular}

\subsection{Monin-Obukhov Length}

This parameter, which includes all the parameters that influence the mechanical phenomena that occur in air, is used to determine the stability, and is considered as a measure (m) of the thickness of the layer of mechanical mixing close to the surface $[33,36]$. This length is given by:

$$
\mathrm{L}=-\frac{\mathrm{v}_{*}^{3} \rho_{\mathrm{a}} \mathrm{ch}_{\mathrm{a}} \mathrm{T}_{\mathrm{r}}}{\mathrm{kgH}}
$$

where $c_{h, a}$ is the heat capacity of air and takes a value $1012 \mathrm{~J} / \mathrm{kgK}, \mathrm{T}_{\mathrm{r}}$ is the air temperature $(\mathrm{K}), \mathrm{g}$ is the acceleration of gravity, and $\rho_{\mathrm{a}}$, is the air density $\left(\mathrm{kg} / \mathrm{m}^{3}\right)$. The Monin-Obukhov length takes positive values for a stable stability, negative values for an unstable one, and infinite for a neutral one.

\subsection{Air Density}

Jones [37] recommends expression (9) for the calculation of air density and for use in standards laboratories. Thereby, the air density depends on the relative humidity (RH), on the ambient temperature $\left(\mathrm{T}_{\mathrm{a}}\right)$, and on the atmospheric pressure at ground level $\left(\mathrm{P}_{0}\right)$.

$$
\rho_{\mathrm{a}}=\frac{0.4646}{\mathrm{~T}_{\mathrm{a}}}\left(0.0075 \mathrm{P}_{0}-0.003796 \cdot R H \cdot 1.3146 \cdot 10^{9} \cdot \mathrm{e}^{-\frac{5315.56}{\mathrm{~T}_{\mathrm{a}}}}\right) .
$$

\subsection{Air Temperature Profile}

There is also turbulence of a thermal origin, due to the vertical movements of the air caused by thermal gradients and to which atmospheric stability is traditionally associated. Mechanical and thermal turbulence occur simultaneously, contributing to the genesis and intensity of the global atmospheric turbulence. Given the turbulence of a thermal origin, air rises toward regions of lower pressure where it expands and cools. Under adiabatic or neutral conditions, the decrease rate in the dry air temperature with the height $(\mathrm{dT} / \mathrm{dz})$, one of the main constants in meteorology that is taken as a reference for real cases (not adiabatic), has the value $\mathrm{dT} / \mathrm{dz} \approx 0.01{ }^{\circ} \mathrm{C} / \mathrm{m}$ or $1{ }^{\circ} \mathrm{C} / 100 \mathrm{~m}[38,39]$. The potential temperature of dry air $(\theta)$ is defined as that reached by an infinitesimal air volume when it is transported adiabatically from its pressure $\left(\mathrm{P}_{\mathrm{z}}\right)$ to a reference pressure (surface pressure the earth, $\mathrm{P}_{0}$ ). Its value, from the adiabatic relation $\mathrm{T}-\mathrm{P}_{\mathrm{z}}$, is

$$
\theta=\mathrm{T}\left(\frac{\mathrm{P}_{0}}{\mathrm{P}_{\mathrm{z}}}\right)^{\frac{\gamma-1}{\gamma}}
$$

where $P_{z}(P a)$ is the atmospheric pressure at different heights and $\gamma$ is the adiabatic coefficient of air with a value of 1.4. From this expression, it can be deduced that, at ground level, the ambient temperature and the potential temperature take the same value. The pressure is related to temperature through the following relation

$$
\mathrm{P}_{\mathrm{z}}=\rho_{\mathrm{a}} \mathrm{R}_{\mathrm{g}} \mathrm{T}
$$

where $R_{g}$ is the ideal gas constant. Finally, the potential temperature profile is a function of stability and is given by the following expression [22] 


$$
\frac{\mathrm{d} \theta}{\mathrm{dz}}=-\frac{\mathrm{H}}{\mathrm{u}_{*} \rho_{\mathrm{a}} \mathrm{c}_{\mathrm{p}, \mathrm{a}} \mathrm{k} \mathrm{z}_{\mathrm{ref}}} \phi_{\mathrm{H}}=-\frac{\mathrm{H}}{\mathrm{u}_{*} \rho_{\mathrm{a}} \mathrm{c}_{\mathrm{p}, \mathrm{a}} \mathrm{k} z_{\mathrm{ref}}}\left(\alpha_{3}+\alpha_{4} \frac{\mathrm{z}}{\mathrm{L}}\right)^{\alpha_{5}}
$$

where $\phi_{\mathrm{H}}$ is a turbulent exchange coefficient due to heat [12]. In this way, the temperature profiles are a function of atmospheric stabilities [31]. Thus, for neutral and stable conditions, $\alpha_{3}, \alpha_{4}$, and $\alpha_{5}$ take $0.74,4.7$, and 1 , respectively, and for unstable conditions, $1.83,-16.44$, and -0.5 , respectively [31]. Again, when performing the integral, the integration constant $\left(z_{0}\right)$ appears, which is called the roughness length.

\subsection{Eddy Diffusivities}

The horizontal diffusion coefficients, $\mathrm{K}_{\mathrm{H}}$, and vertical, $\mathrm{K}_{\mathrm{V}},\left(\mathrm{K}_{\mathrm{x}}=\mathrm{K}_{\mathrm{y}}=\mathrm{K}_{\mathrm{H}}\right.$ and $\left.\mathrm{K}_{\mathrm{z}}=\mathrm{K}_{\mathrm{V}}\right)$, known as Eddy diffusivities, express the mechanical turbulent diffusivity. First, we will consider the vertical diffusivity as it is the most complex. For this case, a theory modified by dimensional arguments and stability considerations is applied that implies the convective boundary layer $[2,12,40,41]$. For this layer, the two main variables that control turbulence are the convective boundary layer depth, $\mathrm{z}_{\mathrm{C}}$, and the convective velocity scale, $\mathrm{w}_{*}$. Another important length for the calculation of diffusivities is the boundary layer height, $\mathrm{H}_{\mathrm{b}}$. The vertical transport of polluting material is dominated by turbulent diffusion under convective conditions that depends on different atmospheric conditions $[12,22,40]$. Thus, for stable conditions:

$$
\begin{gathered}
\mathrm{K}_{\mathrm{V}}=\frac{\mathrm{ku}_{* \mathrm{z}}}{0.74+4.7 \frac{\mathrm{z}}{\mathrm{L}}} \mathrm{e}^{-\mathrm{b \eta}} \\
\eta=\frac{\mathrm{z}}{\mathrm{L}} \mu^{-1 / 2} \text { and } \mu=\frac{\mathrm{u}_{*}}{|\mathrm{fL}|}
\end{gathered}
$$

where $\mathrm{b}$ is a constant with a value of 0.91 , and $\mathrm{f}$ is the force or parameter of Coriolis $(\mathrm{f}=2 \omega \operatorname{sen} \phi \approx$ $1.15 \times 10^{-4} \mathrm{~s}^{-1}$, where $\phi$ is the latitude and $\omega$ is the Earth angular velocity) $[12,22]$. For neutral conditions,

$$
\begin{gathered}
\mathrm{K}_{\mathrm{V}}=\mathrm{u}_{*} \mathrm{kze}^{\frac{-4 \mathrm{z}}{\mathrm{H}_{\mathrm{b}}}} \\
\mathrm{H}_{\mathrm{b}}=\mathrm{F} \frac{\mathrm{u}_{*}}{\mathrm{f}}
\end{gathered}
$$

where $\mathrm{F}$ is a factor that varies between 0.25 and 1 and whose recommended value is $0.455[12,22,40]$.

Finally, for unstable conditions [12,22,40,42],

$$
\begin{gathered}
\mathrm{K}_{\mathrm{V}}=\mathrm{w}_{*} \mathrm{z}_{\mathrm{c}}\left[2.5\left(\mathrm{k} \frac{\mathrm{z}}{\mathrm{z}_{\mathrm{c}}}\right)^{4 / 3}\left(1-15 \frac{\mathrm{z}}{\mathrm{L}}\right)^{1 / 4}\right] 0 \leq \frac{\mathrm{z}}{\mathrm{z}_{\mathrm{c}}}<0.05 \\
\mathrm{~K}_{\mathrm{V}}=\mathrm{w}_{*} \mathrm{z}_{\mathrm{c}}\left[0.021+0.408 \frac{\mathrm{z}}{\mathrm{z}_{\mathrm{c}}}+1.352\left(\frac{\mathrm{z}}{\mathrm{z}_{\mathrm{c}}}\right)^{2}-4.096\left(\frac{\mathrm{z}}{\mathrm{z}_{\mathrm{c}}}\right)^{3}+2.56\left(\frac{\mathrm{z}}{\mathrm{z}_{\mathrm{c}}}\right)^{4}\right] \quad 0.05 \leq \frac{\mathrm{z}}{\mathrm{z}_{\mathrm{c}}}<0.6 \\
\mathrm{~K}_{\mathrm{V}}=\mathrm{w}_{*} \mathrm{z}_{\mathrm{C}}\left[0.2 \mathrm{e}^{\left(6-10 \frac{\mathrm{z}}{\mathrm{z}_{\mathrm{c}}}\right)}\right] 0.6 \leq \frac{\mathrm{z}}{\mathrm{z}_{\mathrm{c}}}<1.1 \\
\mathrm{~K}_{\mathrm{V}}=0.001 \mathrm{w}_{*} \mathrm{z}_{\mathrm{c}} \frac{\mathrm{z}}{\mathrm{z}_{\mathrm{c}}} \geq 1.1 \\
\mathrm{w}_{*}=\mathrm{u}_{*}\left(-\frac{1}{\mathrm{k}} \frac{\mathrm{z}_{\mathrm{i}}}{\mathrm{L}}\right)^{1 / 3} .
\end{gathered}
$$

Under unstable conditions, the convective boundary layer depth, $z_{c}$, is the maximum value between two values [42].

$$
\begin{gathered}
\mathrm{z}_{\mathrm{c}}=\max \left(\mathrm{h}_{1}, \mathrm{~h}_{2}\right) \\
\mathrm{h}_{1}=0.3 \frac{\mathrm{u}_{*}}{\mathrm{f}}
\end{gathered}
$$

$h_{2}$ is the lowest value where $\frac{d \theta}{d z}$ takes a positive value. 
Finally, for the case of horizontal diffusivity, $\mathrm{K}_{\mathrm{H}}$, the variation produces negligible changes in the concentration distribution, and so it is assigned a constant value of $50 \mathrm{~m}^{2} / \mathrm{s}[12,43,44]$.

\subsection{Boundary Conditions}

Except for the boundary condition on the ground, a first-class condition (Dirichlet type) is applied to the entire boundary as, with this, the imperviousness of pollutants is also ensured. A medium large enough value is taken so that it can be assumed as infinity. For the surface $(z=0)$, the boundary condition is of the greatest interest due to its location of the deposition of pollutants. In this case, a second-class non-homogeneous condition (Neumann type) is applied, governed by the equation

$$
-K_{v} \frac{\partial c_{p}}{\partial z}=v_{\text {dep }} c_{p} \quad z=0
$$

where $\mathrm{v}_{\text {dep }}$ is the deposition velocity that takes values in a range between 0.0004 and $0.075 \mathrm{~m} / \mathrm{s}$. For this work, a value of $0.02 \mathrm{~m} / \mathrm{s}$ was taken [12].

\section{The Network Model}

The procedure to design a network model is described in Sánchez-Pérez et al. [17,45] and González-Fernández and Alhama [20]. To obtain a clearer design interpretation, the design will be described below. Firstly, the equivalence between the variable and the electric voltage, $c_{p} \equiv V$ is established. Then, each of the distance variables, $x, y$, and $z$, are discretized in different volume elements. Applying the nomenclature in Figure 4, Equation (1) provides the following finite difference, Equation (26).

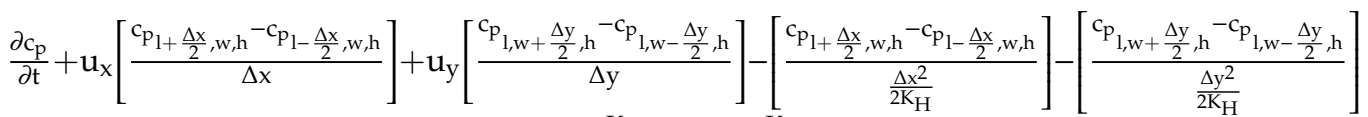

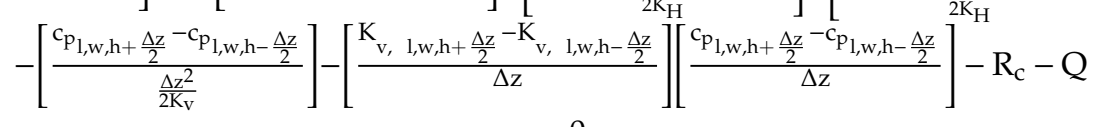

where the subscripts l, w, and h are the space coordinates. To develop Equation (26), we considered that the wind speed practically does not vary with respect to the $x$ and $y$ coordinates and takes a null value in the $\mathrm{z}$ direction. The $\mathrm{K}_{\mathrm{H}}$ variable will also take a constant value.

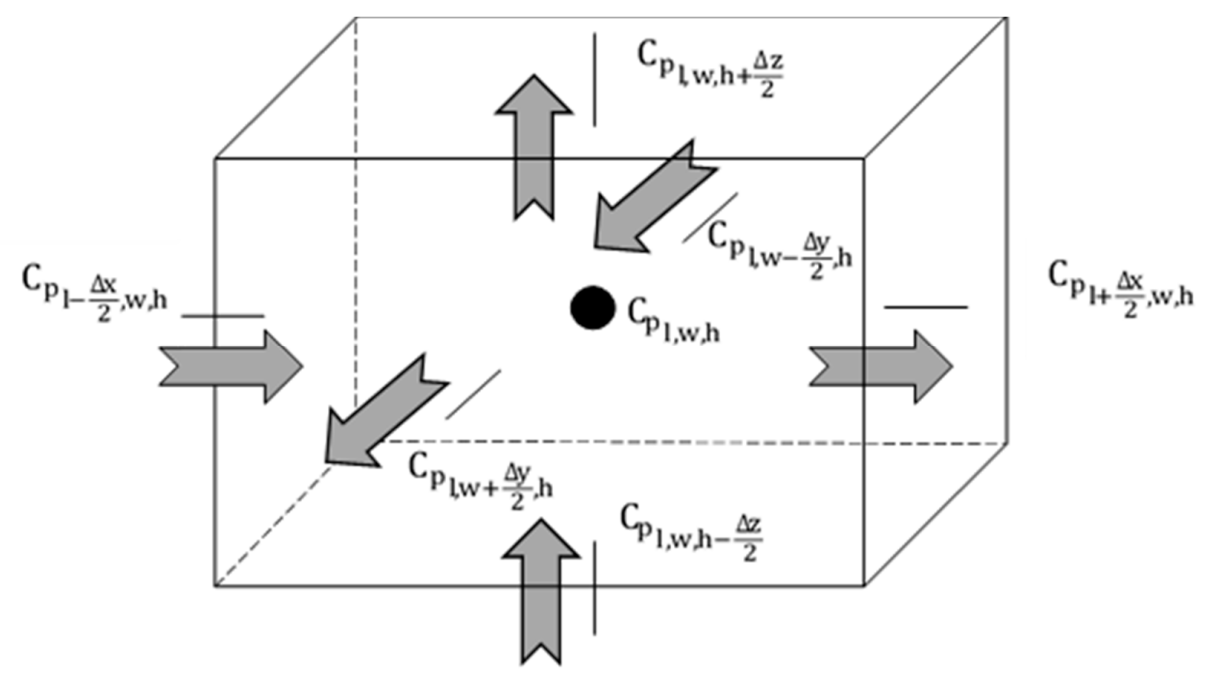

Figure 4. Nomenclature of volume elements. 
Following the scheme of Figure 5, each addend of Equation (26) is an electric current that is balanced at a central node. The fourth, fifth, and sixth addends, that is, the second derivatives, are implemented as simple resistors, $R_{x}, R_{y}$, and $R_{z}$, for each of the spatial coordinates, respectively, where $\mathrm{R}_{\mathrm{x}}=\frac{\Delta \mathrm{x}^{2}}{2 \mathrm{~K}_{\mathrm{H}}}, \mathrm{R}_{\mathrm{y}}=\frac{\Delta \mathrm{y}^{2}}{2 \mathrm{~K}_{\mathrm{H}}}$, and $\mathrm{R}_{\mathrm{z}}=\frac{\Delta \mathrm{z}^{2}}{2 \mathrm{~K}_{\mathrm{v}}}$, and the time derivative are implemented as a capacitor $\left(\mathrm{C}_{\mathrm{r}, \mathrm{i}, \mathrm{j}, \mathrm{k}, \mathrm{K}}\right)$.

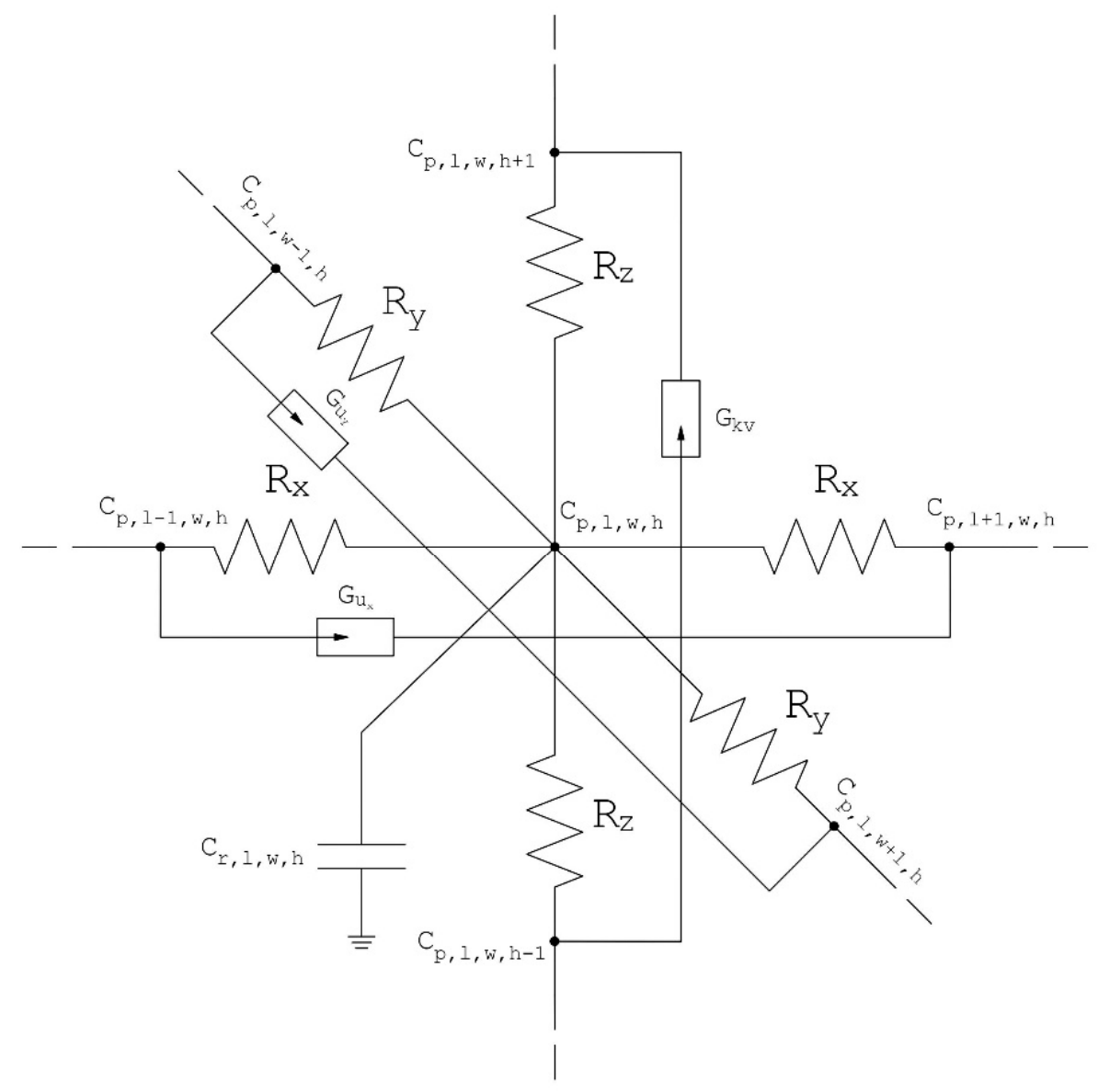

Figure 5. Network model of a volume element.

The rest of the addends are implemented as controlled current sources; however, the last two terms connect from earth to the central node and the terms that imply movement in one direction, wind velocity or diffusivity, connect from one end of the cell to the other, since they imply a direction and a sense. Thus, the terms of a chemical reaction and source or sink of pollutants are given by $\mathrm{I}_{\mathrm{R}_{\mathrm{c}}}=\mathrm{R}_{\mathrm{c}}\left(\mathrm{G}_{\mathrm{R}_{\mathrm{c}}}\right)$ and $\mathrm{I}_{\mathrm{Q}}=\mathrm{Q}\left(\mathrm{G}_{\mathrm{Q}}\right)$, respectively. The terms of velocity and diffusivity are given by

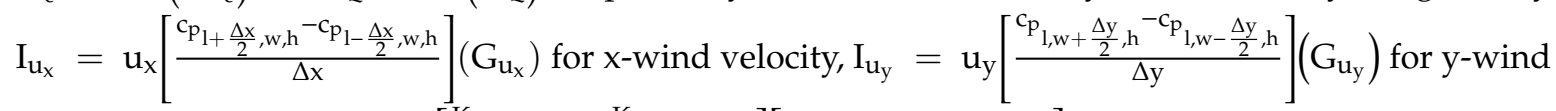

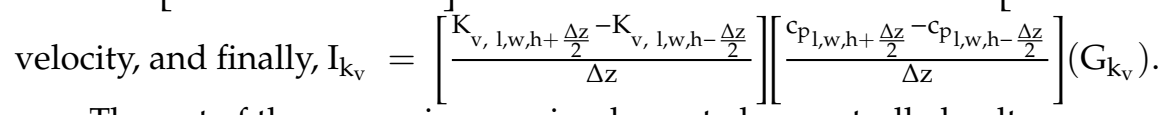

The rest of the expressions are implemented as controlled voltage sources that allow the inclusion of conditioning factors and variable values. These sources, depending on each scenario, choose between the values assigned to Tables 1-4 and select the values for expressions (4) to (7) and (12). Furthermore, they use the appropriate expression between (13), (15), and (17) to (20) for each case or determine the convective boundary layer depth by implementing a conditional code in the source. By allowing these sources to change the values, we can introduce different values that change with time, such as solar radiation, wind velocity, and temperature at the reference height, etc., through expressions or fixed values for a certain time. Finally, the release source and the physical-chemical reactions are implemented as controlled current sources. 
The boundary conditions are implemented as very high value resistors, except for that of the ground, which uses a controlled current source for its implementation. Being an unbounded medium, the meshing must be sufficiently extensive so that the boundary does not influence the concentrations in the positions where we want to know them. As a criterion to choose a suitable mesh, the one where the concentrations in the boundary are practically zero is taken. Finally, to simulate the model, a circuit simulation software, such as NgSpice is used [14,46].

\section{Validation and Results}

To validate the model, we compared it with the experimental results obtained from the literature. Ma et al. [47] used, in their experimental tests, a gaseous pollutant whose density was similar to that of ambient air, so as to not be affected by gravity. These contaminants are known as neutrally-buoyant pollutants [47,48]. In addition, the pollutant does not transform into another compound, so there are no physicochemical reactions. Due to the significant number of variables that must be measured and that also influence the concentration measurement (variable wind velocity and direction, temperature, etc.), the experimental values are not exempt from error. This methodology, derived from the Prairie Grass experimental data, was used to verify and optimize the different emission methods $[47,49]$. Thus, Table 6 shows the input data of the problem [47].

Table 6. Input data of the problem.

\begin{tabular}{cc}
\hline Variable & Case 1 \\
\hline Emission rate $(\mathrm{g} / \mathrm{s})$ & 56.5 \\
Emission source height $(\mathrm{m})$ & 0.46 \\
Wind velocity $(\mathrm{m} / \mathrm{s})$ & 2.87 \\
Wind direction $\left({ }^{\circ}\right)$ & 184 \\
Temperature $\left({ }^{\circ} \mathrm{C}\right)$ & 27.3 \\
Monin-Obukhov Length $(\mathrm{m})$ & 61.54 \\
Pasquill's stability & $\mathrm{E}$ \\
\hline
\end{tabular}

Ma et al. [47] indicated in their article that they used a point source of continuous emission. Therefore, in the simulation, we adjusted the time following the criteria given by Hanna $[39,47,48]$. The simulation presents a scenario composed of a volume of $12,000 \times 2500 \times 100 \mathrm{~m}$ using a fine mesh of $2000 \times 800 \times 5 \mathrm{~m}$ close to the emission source. Figures $6-10$ show the results of the simulation. Figures 6 and 7 are 3D representations with concentrations and two spatial coordinates. Thus, Figure 6 shows the concentration distribution at $0.50 \mathrm{~m}$ of height for a section of 12,000 for the $\mathrm{x}$-coordinate and $2500 \mathrm{~m}$ for the $\mathrm{y}$-coordinate. As can be seen, the concentration falls rapidly to very low values in the first $1000 \mathrm{~m}$. Figure 7 shows the distribution in the $y$ and $z$ coordinates, setting $x$ to a value of $50 \mathrm{~m}$. This figure shows that the concentration starting from $40 \mathrm{~m}$ decays rapidly. For both figures, the concentration distribution on the y axis is symmetric with respect to the emission source. The rest of the figures are representations of the concentrations against a spatial coordinate.

Figure 8 shows the concentration distribution on the $x$-axis in the wind direction with the same coordinates as the source for $\mathrm{x}$ and $\mathrm{y}$. This figure has been used for the validation of the methodology used according to the criteria given by Hanna [39]. Figure 9 illustrates the concentration distribution on the $x$-axis in the direction of the wind at the same height and at $100 \mathrm{~m}$ from the emission source at the y-coordinate. Finally, Figure 10 shows a cross section to the wind direction at $100 \mathrm{~m}$ in the $\mathrm{x}$-coordinate and at the same height as the emission source. These last two figures are the ones that best allow us to observe the behavior of the concentration distribution, particularly the one represented in the wind direction. 
Finally, Table 7 shows the comparison of the results between those obtained by simulation and the experimental values including the ratio or degree of prediction. These values present a ratio that meets the factor of two of the observed values, satisfying the criterion of Hanna to evaluate a model as satisfactory $[39,50]$. The closer the ratio is to the unit, the better the prediction. The worst prediction occurred at $200 \mathrm{~m}$, possibly because the measurement was wrong due to an experimental error, even though the value meets Hanna's criteria [39].

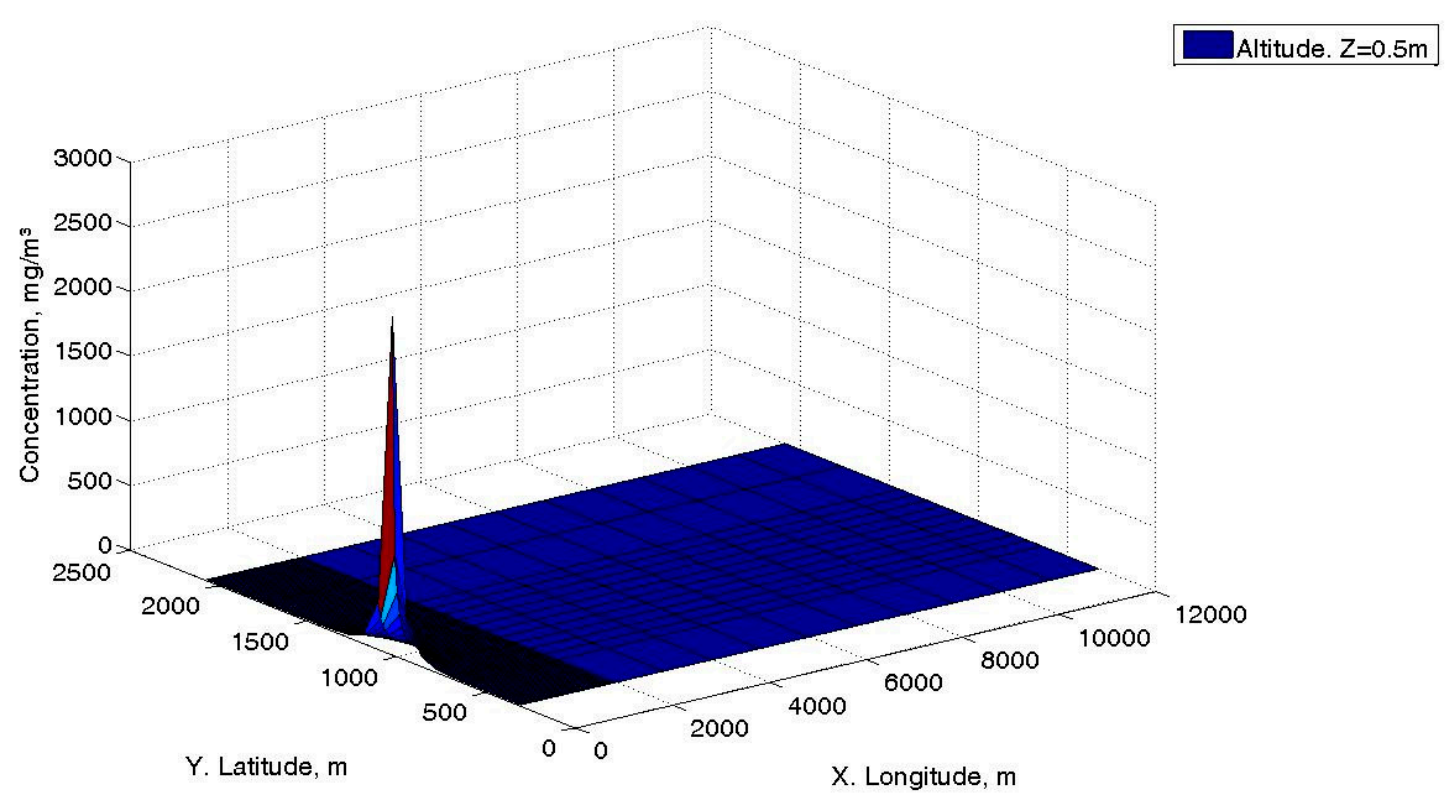

Figure 6. The concentration distribution at a height of $0.46 \mathrm{~m}$ for a section of $12,000 \mathrm{~m}$ of longitude and $2500 \mathrm{~m}$ of latitude for Case 1.

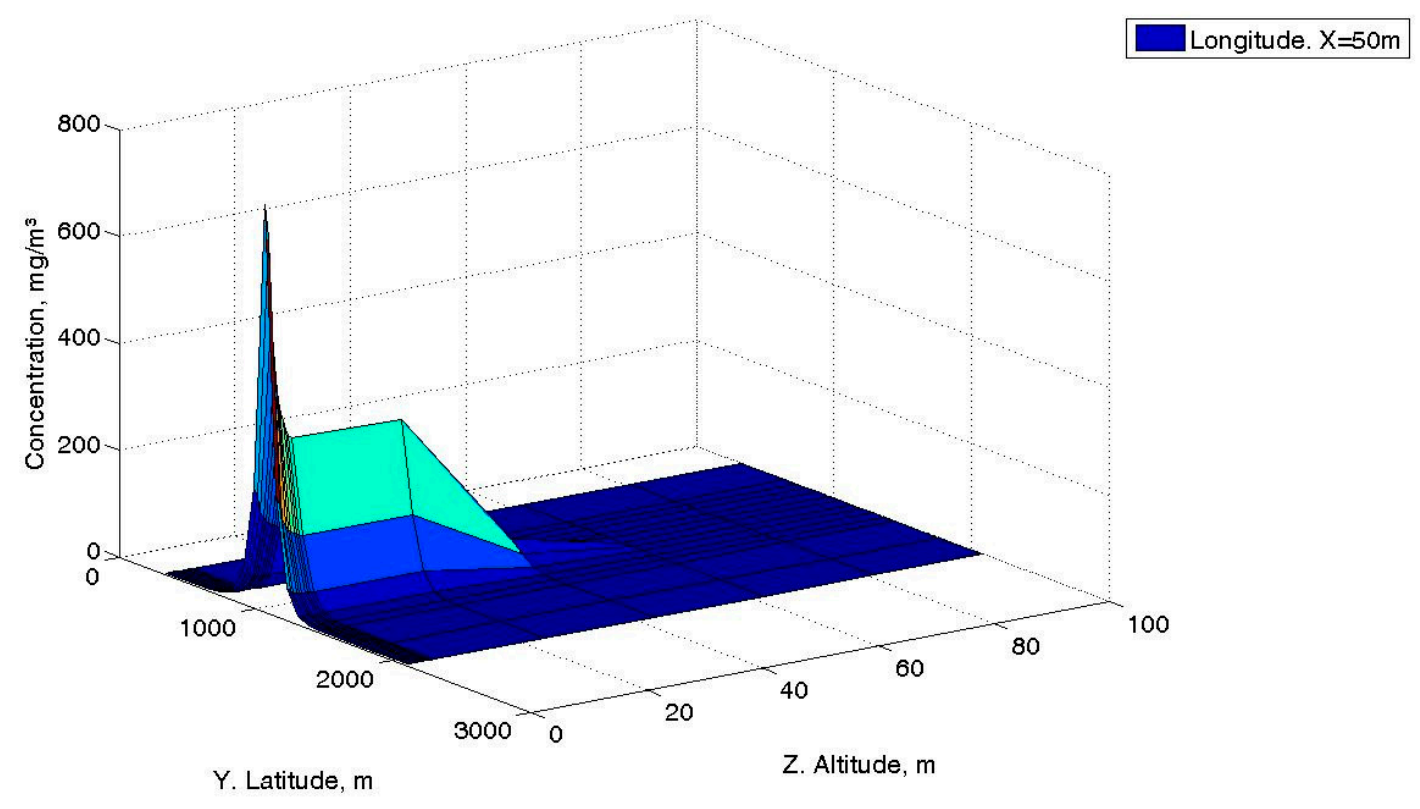

Figure 7. The concentration distribution at a longitude of $50 \mathrm{~m}$ for a section of 100 heights and $2500 \mathrm{~m}$ of latitude for Case 1. 


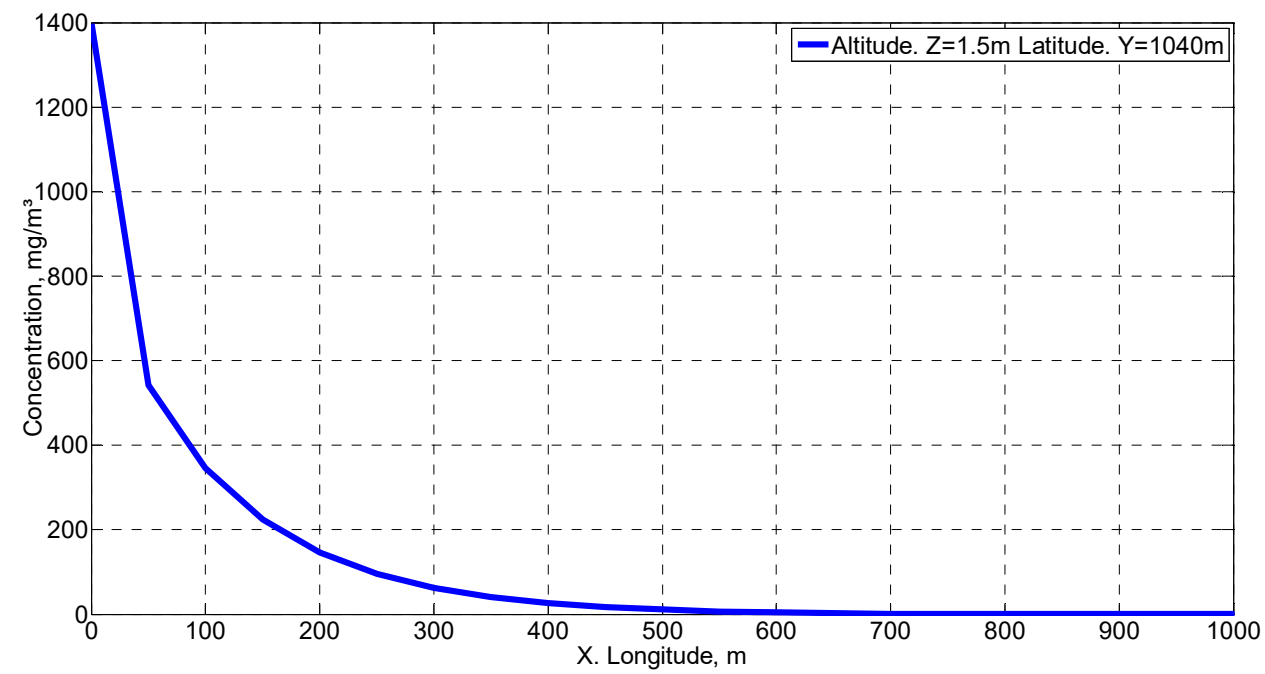

Figure 8. The concentration distribution on the $x$-axis in the wind direction with the same coordinates as the source for $\mathrm{x}$ and $\mathrm{y}$ for Case 1 .

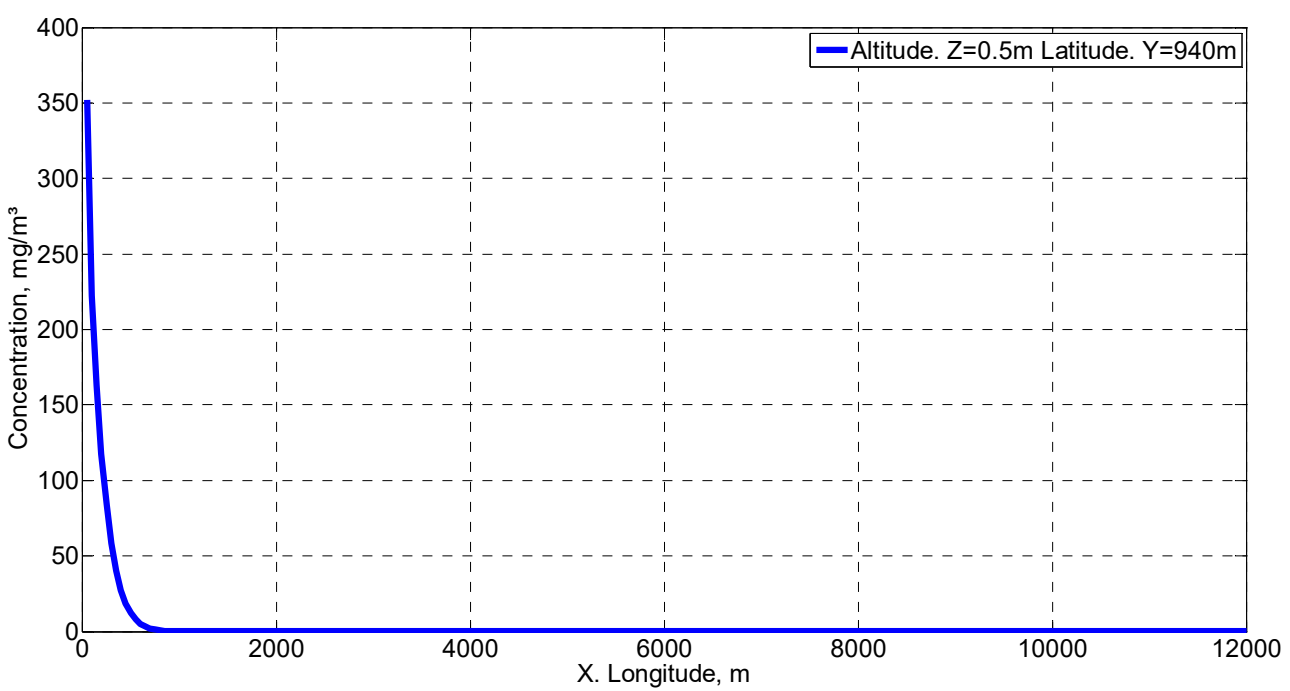

Figure 9. The concentration distribution at $0.50 \mathrm{~m}$ of height and a latitude of $940 \mathrm{~m}$ for Case 1.

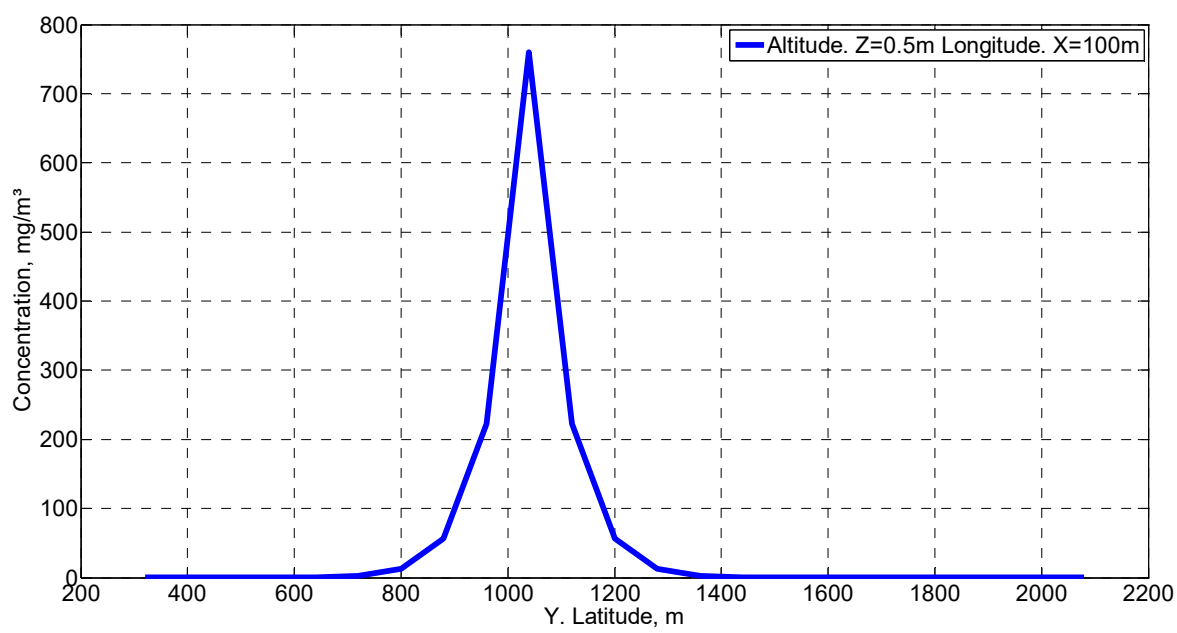

Figure 10. The concentration distribution at $0.50 \mathrm{~m}$ of height and a longitude of $100 \mathrm{~m}$ for Case 1. 
Table 7. Simulated and experimental data comparison for Case 1.

\begin{tabular}{cccc}
\hline Distance $\mathbf{m}$ & Experimental Data $\mathbf{~ m g} / \mathbf{m}^{\mathbf{3}}$ & Simulated Concentration $\mathbf{~} \mathbf{g} / \mathbf{m}^{\mathbf{3}}$ & Ratio \\
\hline 50 & 650 & 542.3 & 0.83 \\
100 & 275 & 346.3 & 1.26 \\
200 & 86 & 146.7 & 1.71 \\
400 & 26 & 26.7 & 1.03 \\
\hline
\end{tabular}

Next, we studied different boundary conditions, both for the wind velocity and for the atmospheric Pasquill's stability categories. First, Case 2 shows a day with moderate insolation and a very low wind velocity; however, for Case 3, it occurs at night with a high wind velocity (Table 8). In both Cases, the emission is continuous. Finally, Case 4 represents an instantaneous emission of one minute where half the mass that is released in Case 1 per minute is released.

Table 8. The input data for Cases 2,3, and 4 .

\begin{tabular}{cccc}
\hline Variable & Case 2 & Case 3 & Case 4 \\
\hline Emission rate $(\mathrm{g} / \mathrm{s})$ & 56.5 & 56.5 & - \\
Mass release $(\mathrm{g})$ & - & - & 1695 \\
Emission source height $(\mathrm{m})$ & 0.46 & 0.46 & 0.46 \\
Wind velocity $(\mathrm{m} / \mathrm{s})$ & 1 & 6 & 2.87 \\
Wind direction $\left({ }^{\circ}\right)$ & 184 & 184 & 184 \\
Temperature $\left({ }^{\circ} \mathrm{C}\right)$ & 27.3 & 27.3 & 27.3 \\
Insolation or period & Strong & Night & Night \\
Pasquill's stability & $\mathrm{B}$ & $\mathrm{D}$ & $\mathrm{E}$ \\
\hline
\end{tabular}

The first case studied (Case 1), which was used for the validation of the model, corresponds to a light breeze with a moderately stable stability category that can produce a fumigation effect [22,51]. As shown in Figure 7, this effect produced a higher concentration than in the rest of the cases studied. The second case (Case 2) corresponds to a practically calm wind with a moderately unstable stability category that produces a dispersion of the pollutant known as "looping", favoring convection phenomena [22,51]. For the height studied, this effect decreased the concentration with respect to the previous case (Figure 11). Finally, Case 3 corresponds to a wind that raises dust or shakes small trees with a neutral stability category that produces a "coning" type dispersion [22,51]. This combination makes the concentration even lower for the position studied than in the previous cases (Figure 12).

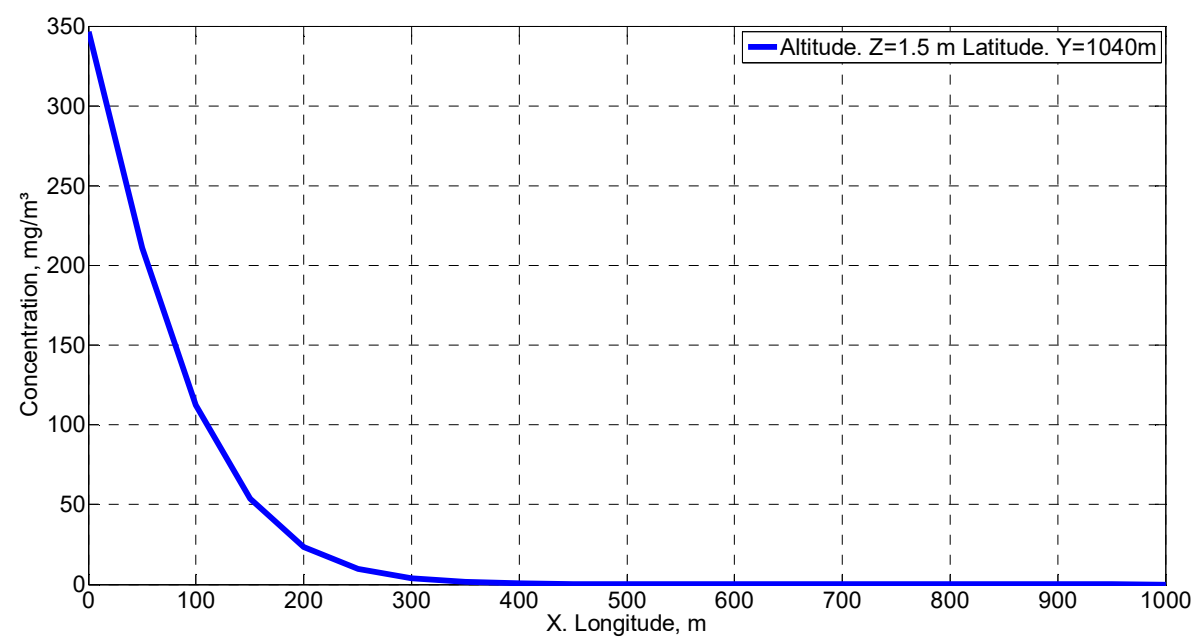

Figure 11. The concentration distribution on the $x$-axis in the wind direction with the same coordinates as the source for $\mathrm{x}$ and $\mathrm{y}$ for Case 2 . 


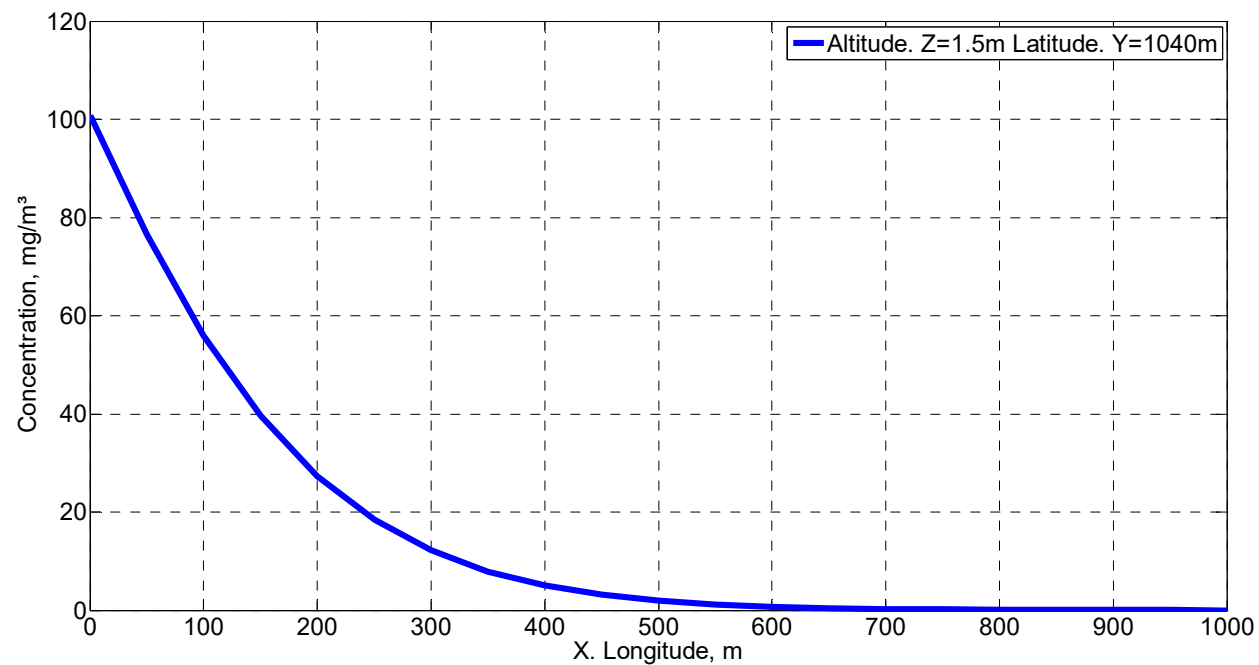

Figure 12. The concentration distribution on the $x$-axis in the wind direction with the same coordinates as the source for $\mathrm{x}$ and $\mathrm{y}$ for Case 3 .

Case 2 would be expected to present a higher concentration near the source as it has a lower wind velocity. However, the possible combination of the fumigation effect of stable conditions and the convective phenomena of its stability make its concentration lower than in Case 1. Finally, if cases 1 and 4 are compared, at positions close to the emission source, approximately half the concentration is obtained in Case 4 (Figure 13) when compared with Case 1 (Figure 8). In more distant positions, the concentration decreased more rapidly in the instantaneous case, possibly by the amount of mass emitted and the release time. Clearly, with increasing time, the concentration of Case 4 decreased as this was an instantaneous emission.

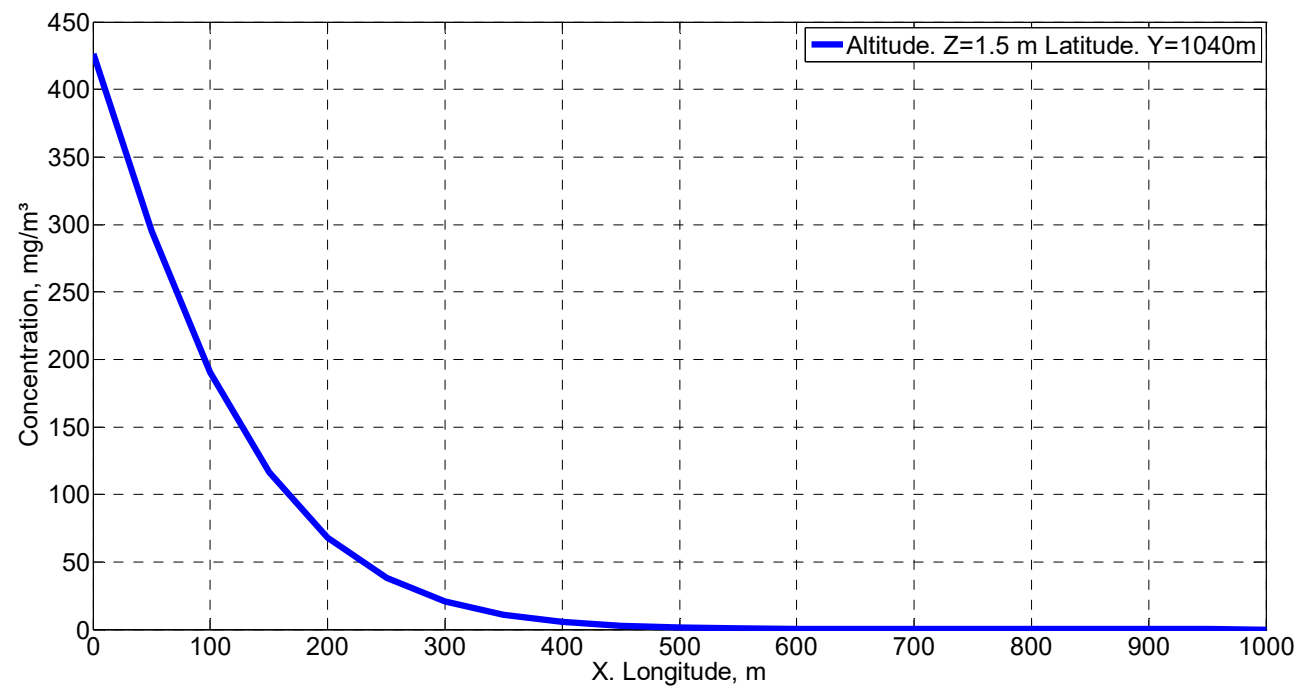

Figure 13. The concentration distribution on the $x$-axis in the wind direction with the same coordinates as the source for $\mathrm{x}$ and $\mathrm{y}$ for Case 4 . 


\section{Conclusions}

This work presents a mathematical model of the diffusion of pollutants emitted from a point source, based on current bibliographies, which encompasses phenomena, such as turbulence, buoyancy forces, drag forces, thermal gradients, and diffusive effects. This model was solved using a numerical model, built using the Network Simulation Method, without linearization of the equations or making assumptions. All the conditioning factors of the mathematical model were implemented, allowing for the choice between the most appropriate equations at all times. In addition, this allows the input values to be variable over time, such as the velocity and direction of the wind, temperature, and atmospheric pressure. The proposed model allows the introduction of pollutant emissions as a function of time, including both instantaneous and continuous emissions with a constant emission value. The model, which was validated with experimental data, meets the criterion of Hanna to evaluate a model as satisfactory. The results obtained from the simulation allow for the attainment of the concentration in a three-dimensional space of a pollutant that has been released by a point source. This model also allows for the representation of the concentration in one or two spatial coordinates, which facilitates understanding of the behavior of the pollutant.

The cases studied demonstrated the great influence that wind velocity and atmospheric stability have on the dispersion of a pollutant, since, a priori, it could be expected that the lower the wind velocity, the greater the concentration near the source of emission. However, the convective phenomena for unstable stability or the possible fumigation effect for stable conditions can make the concentration lower.

The use of precise models in the diffusion of pollutants has two important applications, the first to know, a priori, the behavior of the emission of pollutants, and the second, to know the concentration of a pollutant at various points, through an inverse problem, locating the emission source.

Author Contributions: J.F.S.-P. and M.R.M.-R. are the originators of the initial idea for the work. J.F.S.-P., M.R.M.-R., and M.C. performed the simulations and conceptualizations. J.F.S.-P., M.R.M.-R., and M.C. supervised the entire article. All authors analyzed the data, preformed the formal analysis, and participated in the writing and revising of the manuscript. All authors have read and agreed to the published version of the manuscript.

Funding: This research received no external funding.

Conflicts of Interest: The authors declare no conflict of interest.

\section{References}

1. ASHRAE (American Society of Heating Refrigeration and Air-Conditioning Engineers). Building air intake and exhaust design. In ASHRAE Handbook Heating, Ventiating and Air-Conditioning Aplications; ASHRAE: Atlanta, GA, USA, 2007.

2. Lateb, M.; Meroney, R.N.; Yataghene, M.; Fellouah, H.; Saleh, F.; Boufadel, M.C. On the use of numerical modelling for near-field pollutant dispersion in urban environments-A review. Environ. Pollut. 2016, 208, 271-283. [CrossRef]

3. Roberts, O.F. The theoretical scattering of smoke in a turbulent atmosphere. Proc. R. Soc. London. Ser. A Contain. Pap. Math. Phys. Character 1923, 104, 640-654.

4. Sutton, O.G. Micrometeorology; McGraw-Hill: New York, NY, USA, 1953.

5. Pasquill, F. The Estimation of the Dispersion of Windborne Material. Meteorol. Mag. 1961, 90, $33-40$.

6. Pasquill, F. Some observed properties of medium-scale diffusion in the atmosphere. Q. J. R. Meteorol. Soc. 1962, 88, 70-79. [CrossRef]

7. Pasquill, F. Atmospheric Dispersion Models for Environmental Pollution Applications. In Lectures on Air Pollution and Environmental Impact Analyses; American Meteorological Society: Boston, MA, USA, 1982; ISBN 978-1-935704-23-2.

8. Gifford, F. Small-scale turbulent diffusion in the atmosphere. Nature 1961, 190, 248. [CrossRef]

9. Turner, D.B. A Diffusion Model for an Urban Area. J. Appl. Meteorol. 1964, 3, 83-91. [CrossRef]

10. Slade, D.H. (Ed.) Meteorology and atomic energy 1968. Air Resources Laboratory, ESSA, for USAEC Division of Technical Information. Pp. 445; 234 Figures; 60 Tables. \$3. Q. J. R. Meteorol. Soc. 1969, 95, 446. [CrossRef] 
11. Turner, J.S. Buoyancy effects in fluids. In Buoyancy Effects in Fluids; Cambridge University Press: Cambridge, UK, 1973.

12. Ku, J.Y.; Rao, S.T.; Rao, K.S. Numerical simulation of air pollution in urban areas: Model development. Atmos. Environ. 1987, 21, 201-212. [CrossRef]

13. WHO. Ambient (Outdoor) Air Pollution. Available online: https://www.who.int/en/news-room/fact-sheets/ detail/ambient-(outdoor)-air-quality-and-health (accessed on 20 September 2020).

14. Sourceforge. NgSpice. Available online: http://ngspice.sourceforge.net/index.html (accessed on 20 September 2020).

15. Sánchez Pérez, J.F.; Moreno, J.A.; Alhama, F. Numerical Simulation of High-Temperature Oxidation of Lubricants Using the Network Method. Chem. Eng. Commun. 2015, 202, 982-991. [CrossRef]

16. Sánchez, J.F.; Alhama, F.; Moreno, J.A. An efficient and reliable model based on network method to simulate $\mathrm{CO}_{2}$ corrosion with protective iron carbonate films. Comput. Chem. Eng. 2012, 39, 57-64. [CrossRef]

17. Sánchez-Pérez, J.F.; Marín, F.; Morales, J.L.; Cánovas, M.; Alhama, F. Modeling and simulation of different and representative engineering problems using network simulation method. PLoS ONE 2018, 13, e0193828. [CrossRef] [PubMed]

18. García-Ros, G.; Alhama, I.; Cánovas, M. Powerful software to Simulate soil Consolidation problems with prefabricated Vertical Drains. Water 2018, 10, 242. [CrossRef]

19. Zueco, J.; Alhama, F. Inverse estimation of temperature dependent emissivity of solid metals. J. Quant. Spectrosc. Radiat. Transf. 2006, 101, 73-86. [CrossRef]

20. González-Fernández, C.F.; Alhama, F. Heat Transfer and the Network Simulation Method; Horno, J., Ed.; Transworld Research Network: Trivandrum, India, 2001.

21. Sánchez-Pérez, J.F.; Nicolas, J.A.M.; Alhama, F.; Canovas, M. Study of transition zones in the carbon monoxide catalytic oxidation on platinum using the network simulation method. Mathematics 2020, 8, 1413. [CrossRef]

22. Frank, L. Lees' Loss Prevention in the Process Industries; Elsevier: Amsterdam, The Netherlands, 2012.

23. Moradpour, M.; Afshin, H.; Farhanieh, B. A numerical investigation of reactive air pollutant dispersion in urban street canyons with tree planting. Atmos. Pollut. Res. 2017, 8, 253-266. [CrossRef]

24. Albani, R.A.S.; Duda, F.P.; Pimentel, L.C.G. On the modeling of atmospheric pollutant dispersion during a diurnal cycle: A finite element study. Atmos. Environ. 2015, 118, 19-27. [CrossRef]

25. Seinfeld, J.H.; Pandis, S.N. Atmospheric Chemistry and Physics: From Air Pollution to Climate Change; Wiley: Hoboken, NJ, USA, 2006.

26. Rabeiy, R.E. Spatial Modeling of Heavy Metal Pollution of Forest Soils in a Historical Mining Area Using Geostatistical Methods and Air Dispersion Modeling; Technischen Universität Clausthal: Clausthal-Zellerfeld, Germany, 2010.

27. Holtslag, A.A.M.; Van Ulden, A.P. A simple scheme for daytime estimates of the surface fluxes from routine weather data. J. Clim. Appl. Meteorol. 1983, 22, 517-529. [CrossRef]

28. Clarke, R.H. A Model for Short and Medium Range Dispersion of Radionuclides Released to the Atmosphere; National Radiological Protection Board: Harwell, UK, 1979.

29. ASME PTC Committee. Standard for Verification and Validation in Computational Fluid Dynamics and Heat Transfer: ASME VEV 20; American Society of Mechanical Engineers: New York, NY, USA, 2009; ISBN 9780791832097. Available online: https://www.asme.org/codes-standards/find-codes-standards/v-v-20-standard-verificationvalidation-computational-fluid-dynamics-heat-transfer (accessed on 20 September 2020).

30. von Karman, T. Progress in the Statistical Theory of Turbulence. Proc. Natl. Acad. Sci. USA 1948, 34, 530-539. [CrossRef]

31. Businger, J.A.; Wyngaard, J.C.; Izumi, Y.; Bradley, E.F. Flux- profile relationships in the atmospheric surface layer. J. Atmos. Sci. 1971, 28, 181-189. [CrossRef]

32. Nagib, H.M.; Chauhan, K.A. Variations of von Kármán coefficient in canonical flows. Phys. Fluids 2008. [CrossRef]

33. Monin, A.S.; Obukhov, A.M. Basic laws of turbulent mixing in the surface layer of the atmosphere. Contrib. Geophys. Inst. Acad. Sci. USSR 1954, 151, 163-187.

34. Dyer, A.J.; Hicks, B.B. Flux-gradient relationships in the constant flux layer. Q. J. R. Meteorol. Soc. 1970, 96, 715-721. [CrossRef]

35. Webb, E.K. Profile relationships: The log-linear range, and extension to strong stability. Q. J. R. Meteorol. Soc. 1970, 96, 67-90. [CrossRef] 
36. Leelőssy, Á.; Molnár, F.; Izsák, F.; Havasi, Á.; Lagzi, I.; Mészáros, R. Dispersion modeling of air pollutants in the atmosphere: A review. Cent. Eur. J. Geosci. 2014, 6, 257-278. [CrossRef]

37. Jones, F.E. Air density equation and the transfer of the mass unit. J. Res. Natl. Bur. Stand. 1978, 83, 419. [CrossRef]

38. Sutton, O.G. A theory of eddy diffusion in the atmosphere. Proc. R. Soc. A 1932, 135, 143-165.

39. Hanna, S.R. Handbook on Atmospheric Diffusion Models; U.S. Department of Commerce: Washington, DC, USA, 1981.

40. Shir, C.C. A Preliminary Numerical Study of Atmospheric Turbulent Flows in the Idealized Planetary Boundary Layer. J. Atmos. Sci. 1973, 30, 1327-1339. [CrossRef]

41. Dimitrova, R.; Fernando, H.J.S.; Silver, Z.; Leo, L.S.; Hocut, C.; Zsedrovits, T.; Di Sabatino, S. Modification of the Yonsei university boundary layer scheme in the WRF model for stable conditions. In Proceedings of the HARMO 2014-16th International Conference on Harmonisation within Atmospheric Dispersion Modelling for Regulatory Purposes, Varna, Bulgaria, 8-11 September 2014.

42. Aliabadi, A.A.; Staebler, R.M.; De Grandpré, J.; Zadra, A.; Vaillancourt, P.A. Comparison of Estimated Atmospheric Boundary Layer Mixing Height in the Arctic and Southern Great Plains under Statically Stable Conditions: Experimental and Numerical Aspects. Atmos. Ocean 2016, 54, 60-74. [CrossRef]

43. Reynolds, S.D.; Sienfeld, J.H.; Roth, P.M. Mathematical modeling of photochemical air pollution-1. formulation of the model. Atmos. Environ. 1973, 7, 1033-1061. [CrossRef]

44. McRae, G.J.; Goodin, W.R.; Seinfeld, J.H. Development of a second-generation mathematical model for Urban air pollution-I. Model formulation. Atmos. Environ. 1982, 16, 679-696. [CrossRef]

45. Sanchez Perez, J.F.; Conesa, M.; Alhama, I. Solving ordinary differential equations by electrical analogy: A multidisciplinary teaching tool. Eur. J. Phys. 2016, 37, 065703. [CrossRef]

46. Nagel, L.W. SPICE2: A Computer Program To Simulate Semiconductor Circuits. Ph.D. Thesis, University California, Berkeley, CA, USA, 1975.

47. Ma, D.; Deng, J.; Zhang, Z. Comparison and improvements of optimization methods for gas emission source identification. Atmos. Environ. 2013, 81, 188-198. [CrossRef]

48. Jones, R.; Lehr, W.; Simecek-Beatty, D.; Reynolds, R.M. Aloha @(Areal Locations of Hazardous Atmospheres) 5.4.4; U.S. Department of Commerce: Washington, DC, USA, 2013.

49. Barad, M.L. Project Prairie Grass: A Field Program in Diffusion Vol II; Geophysical Research Paper Bedford; Air Force Cambridge Research Center: Cambridge, MA, USA, 1958.

50. Goyal, P.; Kumar, A. Mathematical Modeling of Air Pollutants: An Application to Indian Urban City. Air Qual. Models Appl. 2011. [CrossRef]

51. Gifford, F.A. Turbulent diffusion-typing schemes: A review. Nucl. Saf. 1976, 17, 68-86.

Publisher's Note: MDPI stays neutral with regard to jurisdictional claims in published maps and institutional affiliations.

(C) 2020 by the authors. Licensee MDPI, Basel, Switzerland. This article is an open access article distributed under the terms and conditions of the Creative Commons Attribution (CC BY) license (http://creativecommons.org/licenses/by/4.0/). 